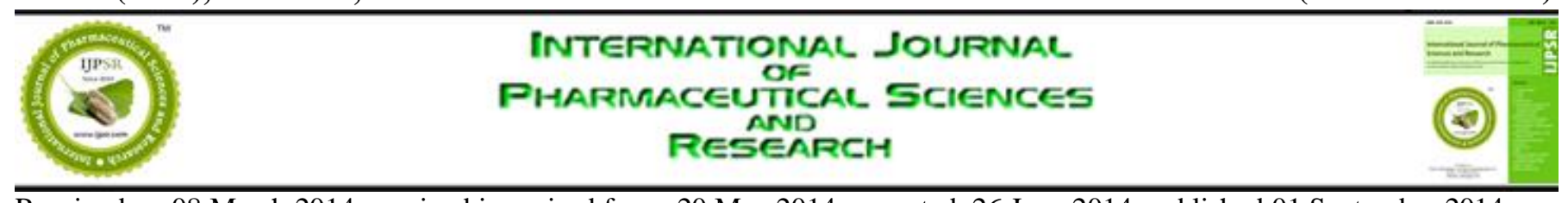

Received on 08 March 2014; received in revised form, 20 May 2014; accepted, 26 June 2014; published 01 September 2014

\title{
A NEW RP-HPLC STABILITY INDICATING METHOD DEVELOPMENT AND VALIDATION FOR SIMULTANEOUS ESTIMATION OF IBUPROFEN \& FAMOTIDINE IN BULK AS WELL IN PHARMACEUTICAL DOSAGES FORM BY USING PDA DETECTOR
}

\author{
S. Ashutosh Kumar ${ }^{* 1}$, Manidipa Debnath ${ }^{2}$, J. V. L. N. Seshagiri Rao ${ }^{3}$ and D. Gowri Sankar ${ }^{4}$
}

Department of Pharmaceutical Analysis \& Quality Assurance ${ }^{1}$, Department of Pharmaceutics ${ }^{2}$, A. K. R. G. College of Pharmacy, Nallajerla, West Godavari - 534112, Andhra Pradesh, India.

Department of Pharmaceutical Analysis, Yalamarty College of Pharmacy ${ }^{3}$, Tarluwada Visakhapatnam 530052, Andhra Pradesh, India.

Department Pharmaceutical Analysis, College of Pharmaceutical Sciences 4, Andhra University, Visakhapatnam - 530003, Andhra Pradesh, India.

Keywords:

HPLC, Ibuprofen, Famotidine, Accuracy, LOD, LOQ, ICH guideline

\section{Correspondence to Author:}

\section{S. Ashutosh Kumar}

Department of Pharmaceutical Analysis \& Quality Assurance, A. K. R. G. College of Pharmacy, Nallajerla, West Godavari - 534112, Andhra Pradesh, India.

E-mail: ashu.mpharm2007@gmail.com

\begin{abstract}
The RP-HPLC separation was carried out by reverse phase chromatography on XTerra column C18 $(4.6 \times 150 \mathrm{~mm}, 3.5 \mu \mathrm{m}$ Make: ACE) or equivalent with a mobile phase composed Sodium Dihydrogen Ortho Phosphate and the $\mathrm{pH}$ has been adjusted to 2.5 by Orthophosporic Acid \& Acetonitrile in the ratio of 30:70 $\mathrm{v} / \mathrm{v}$ in isocratic mode at a flow rate of $1.2 \mathrm{ml} / \mathrm{min}$. The run time was maintained for 8 mins. The detection was monitored at $236 \mathrm{~nm}$. The Accuracy was calculated, and the $\%$ Recovery was found $98.4 \%$ - $101.8 \%$ for the drug Ibuprofen \& $98.4 \%-100.5 \%$ for the drug Famotidine respectively, and reproducibility was found to be satisfactory. The calibration curve for Ibuprofen was linear from 100 to $200 \mathrm{ppm}$ for the drug Ibuprofen \& 3.32-6.65 ppm for the drug Famotidine, respectively. The inter-day and intra-day precision were found to be within limits. The proposed method has adequate sensitivity, reproducibility, and specificity for the determination of Ibuprofen \& Famotidine in bulk and its tablet dosage forms. The limit of detection and limit of quantification for Ibuprofen were found to be $0.18 \mu \mathrm{g} / \mathrm{ml}$ and $0.63 \mu \mathrm{g} / \mathrm{ml}$, respectively. The limit of detection and limit of quantification for Famotidine were found to be $0.046 \mu \mathrm{g} / \mathrm{ml}$ and $0.15 \mu \mathrm{g} / \mathrm{ml}$, respectively. The method was applied for the determination of Ibuprofen and Famotidine in the presence of their degradation products formed under a variety of stress conditions. The bulk active pharmaceutical ingredient was subjected to thermal, hydrolytic (acidic and basic) and oxidative stress conditions and stressed samples were analyzed by the proposed method. The proposed method is simple, fast, accurate, and precise for the quantification of Ibuprofen \& Famotidine in the dosage form, bulk drugs as well as for routine analysis in quality control.
\end{abstract}

INTRODUCTION: Ibuprofen (IB) ((2RS)-2-[4(2-Methylpropyl) phenyl] propanoic acid) is a nonsteroidal anti-inflammatory drug, which is available in $400 \mathrm{mg}, 600 \mathrm{mg}$, and $800 \mathrm{mg}$ tablets for oral administration.

\begin{tabular}{|l|c|}
\hline QUICK RESPONSE CODE & DOI: \\
\hline DOI link: http://dx.doi.org/10.13040/IJPSR.0975-8232.5(9).3829-39 \\
\hline
\end{tabular}

It is indicated for relief of the signs and symptoms of rheumatoid arthritis and osteoarthritis for relief of mild to moderate pain and also indicated for the treatment of primary dysmenorrhea. The empirical formula for Ibuprofen is $\mathrm{C}_{13} \mathrm{H}_{18} \mathrm{O}_{2}$, and its molecular weight is $206.29^{1-3}$.

Famotidine (FM), 3-(((2-)((aminoiminomethyl) amino) - 4 - thiazolyl) methyl) thio) - N'(aminosulfonyl) propanimidamide is a potent, competitive, and reversible inhibitor of histamine action at the $\mathrm{H}_{2}$ receptor. It is used for the treatment of duodenal and gastric ulcers. 
The empirical formula of Famotidine is $\mathrm{C}_{8} \mathrm{H}_{15} \mathrm{~N}_{7} \mathrm{O}_{2} \mathrm{~S}_{3}$ and its molecular weight is 337.43 . Famotidine is available in $20 \mathrm{mg}$ and $40 \mathrm{mg}$ for oral administration ${ }^{4-6}$. To the best of our knowledge, few liquid chromatography procedures were described for the individual determination of Ibuprofen Fig. 1 \& Famotidine Fig. 2, these procedures were developed to estimate either Ibuprofen or Famotidine individually and from formulation or plasma, whereas no single method has been reported for their simultaneous estimation from the formulation. Hence, it is necessary to develop a stability indicating, rapid, accurate and validated LC method for the simultaneous determination of Ibuprofen and Famotidine from combined dosage form for generic drug development. A literature survey regarding the

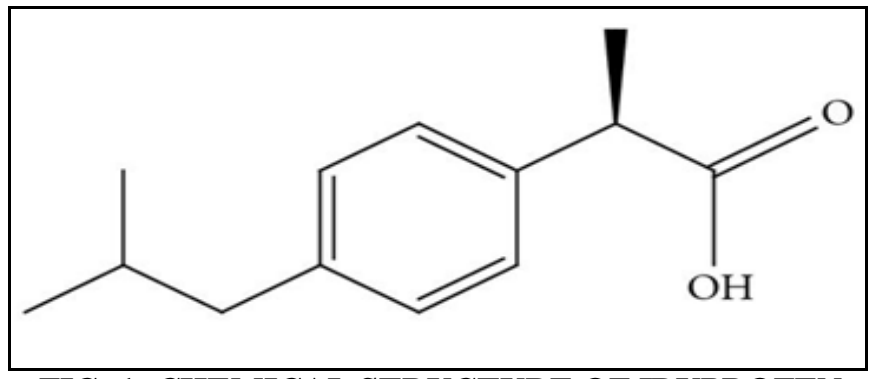

FIG. 1: CHEMICAL STRUCTURE OF IBUPROFEN

\section{MATERIALS AND METHOD: ${ }^{16}$}

Chemicals and Reagents Used: The following chemicals were procured for the process: Water [HPLC Grade], Methanol [HPLC Grade], Acetonitrile [HPLC Grade], Ibuprofen and Famotidine [Working standards], Orthophosphoric Acid \& Sodium Dihydrogen Ortho Phosphate all the chemicals were procured from Standard Solutions. $\mathrm{HCl}$ procured from Finar Chemical Limited, $\mathrm{NaOH}$ procured from SD Fine- Chem Limited \& $\mathrm{H}_{2} \mathrm{O}_{2}$ procured from Alpha Pharma Limited for the study and the tablets were collected from the Local market.

\section{Apparatus and Chromatographic Conditions:}

Equipment: High-performance liquid chromatography equipped with Auto Sampler and DAD or UV detector.

\section{UV/VIS Spectrophotometer: LAB INDIA UV $3000^{+}$}

pH Meter: Adwa - AD 1020

Weighing Machine: Afcoset ER-200A quantitative analysis of these drugs revealed that attempts had been made to develop analytical methods for the estimation of ibuprofen alone and in combination with other drugs by liquid chromatographic (LC) ${ }^{7}$, HPTLC ${ }^{8-10}$, supercritical fluid chromatography ${ }^{11}$, and Spectrophotometric methods ${ }^{12}$. Famotidine is official in British Pharmacopoeia and the United States Pharmacopoeia. A literature survey revealed that liquid chromatographic (LC) ${ }^{13}$, HPTLC ${ }^{14}$ and Spectrophotometric methods ${ }^{15}$ had been reported for the estimation of famotidine. There is no method reported for the estimation of IBU and FAM in the combined dosage form. The present study involves the development and validation of a liquid chromatographic method for the estimation of IBU and FAM in the combined dosage form.

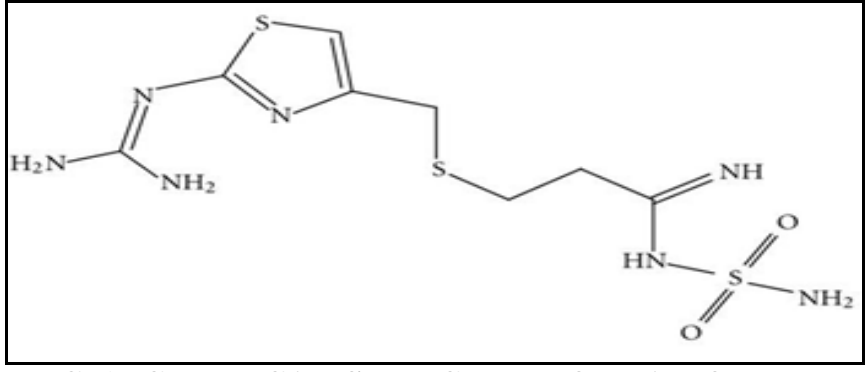

FIG. 2: CHEMICAL STRUCTURE OF FAMOTIDINE

Temperature: Ambient

Column: XTerra column C18 $(4.6 \times 150 \mathrm{~mm}, 3.5$ $\mu \mathrm{m})$

Phosphate Buffer: 2.5 milligrams of Sodium Dihydrogen Ortho Phosphate in $1000 \mathrm{ml}$ Water [HPLC Grade] pH adjusted with Orthophosphoric Acid.

pH: 2.5

Mobile Phase: Phosphate Buffer: Acetonitrile (30: $70 \mathrm{v} / \mathrm{v}$ )

Flow Rate: $1.2 \mathrm{ml}$ per min

Wavelength: $236 \mathrm{~nm}$

Injection Volume: $20 \mu 1$

Run Time: 8 min.

Preparation of Phosphate Buffer: The buffer solution was prepared by dissolving accurately weighed 2.5 milligrams of Sodium Dihydrogen 
Ortho Phosphate and transferred into a clean and dry $1000 \mathrm{ml}$ volumetric flask, dissolved and diluted with $1000 \mathrm{ml}$ water [UPLC Grade]. The final $\mathrm{pH}$ of the buffer was adjusted to 2.5 by using Orthophosphoric acid.

Preparation of Mobile Phase: The Mobile Phase was prepared by mixing $300 \mathrm{ml}(30 \%)$ of the above buffer and $700 \mathrm{ml}$ of Acetonitrile [UPLC Grade] (70\%) and degassed in an ultrasonic water bath for 10 minutes. Then the resultant solution was filtered through a $0.45 \mu$ filter under vacuum filtration.

Diluent Preparation: The Mobile phase was used as Diluent.

\section{Preparation of the Ibuprofen and Famotidine Standard \& Sample Solution:}

Preparation of Stock Solution: The stock solution was prepared by weighing accurately 10mg Ibuprofen \& Famotidine and transferred into a clean and dry $100 \mathrm{ml}$ volumetric flask. About $70 \mathrm{ml}$ of diluent was added and sonicated. The volume was made up to the mark with the same diluent. From the above-prepared Stock solution pipette out $0.49 \mathrm{ml} \& 1.5 \mathrm{ml}$ of the solution and transferred into a clean and dry $10 \mathrm{ml}$ volumetric flask, the diluent was added to the mark to get final concentration.

Preparation of Sample Solution: The sample solution was prepared by weighing equivalently $10 \mathrm{mg}$ of Ibuprofen \& Famotidine and transferred into a $100 \mathrm{ml}$ clean and dry volumetric flask, and about $70 \mathrm{ml}$ of diluent was added and sonicated to dissolve it completely, and the volume made up to the mark with the same solvent.

From above-prepared stock solution pipette out 1.5 $\mathrm{ml}$ of solution and transferred into a clean and dry $10 \mathrm{ml}$ volumetric flask, the diluent was added to the mark $10 \mathrm{ml}$ to get final concentration. The standard and sample solutions were injected five times, and the peak areas were recorded. The mean and percentage relative standard deviation were calculated from the peak areas.

System Suitability: The Tailing factor for the peaks due to Ibuprofen and Famotidine in Standard solution should not be more than 1.5. The Theoretical plates for the Ibuprofen and Famotidine peaks in Standard solution should not be less than 2000. The system suitability of the method was checked by injecting five different preparations of the Ibuprofen and Famotidine standard. The parameters of system suitability were checked.

Assay calculation for Ibuprofen \& Famotidine:

$$
\text { Assay } \%=\frac{A T}{A S} \times \frac{W S}{D S} \times \frac{D T}{W T} \times \frac{P}{100} \times \frac{\text { Avg.Wt. }}{\text { LabelClaim }} \times 100
$$

Where:

$\mathrm{AT}=$ Average area counts of sample preparation.

AS = Average area counts of the standard preparation.

$\mathrm{WS}=$ Weight of working standard taken in mg.

$\mathrm{WT}=$ Weight of the test taken in $\mathrm{mg}$.

DS $=$ Dilution of standard solution

DT $=$ Dilution of sample solution

$\mathrm{P}=$ Percentage purity of working standard

System Suitability Results for Ibuprofen: The Tailing factor obtained from the standard injection was 1.3 .

The Theoretical Plates obtained from the standard injection was 3894.8.

\section{Assay Result for Ibuprofen:}

$29797433 /(2972766) \times 10 / 100 \times 1 / 1 \times 5 / 10 \times 100 /$ $(31.04) \times 1 / 1 \times 10 / 5 \times(99.9) / 100 \times(155.2) / 50 \times 100=$ $100.1 \%$

System Suitability Results for Famotidine: The Tailing factor obtained from the standard injection was 1.3.

The Theoretical Plates obtained from the standard injection was 2775.1 .

\section{Assay Results for Famotidine:}

$116733 /(117283) \times 10 / 100 \times 1 / 1 \times(0.5) / 10 \times 100 /$ $(310.4) \times 1 / 1 \times 10 /(0.5) \times(99.8) / 100 \times(155.2) / 5 \times 100=$ 99.4

Validation Development: ${ }^{17-19}$

Precision: It is a measure of the degree of repeatability of an analytical method under normal operation and it is normally expressed as \% of relative standard deviation (\% RSD). The standard solution was injected five times and measured the area for all five injections in HPLC. The \% RSD for the area of five replicate injections was found to be within the specified limits Table 3 and 4. 


\section{Intermediate:}

Precision / Ruggedness: To evaluate the intermediate precision (also known as Ruggedness) of the method, Precision was performed on a different day by using different make column of same dimensions. The standard solution was injected five times and measured the area for all five injections in UPLC. The \% RSD for the area of five replicate injections was found to be within the specified limits Table 5 and 6.

Accuracy: The accuracy of an analytical procedure expresses the closeness of agreement between the value which is accepted either as a true conventional value or an accepted reference value and value found. The standard solution with Accuracy $-50 \%$, Accuracy $-100 \%$ and Accuracy $150 \%$ was injected into the chromatographic system and calculated the amount found and amount added for Ibuprofen and Famotidine and further calculated the individual recovery and mean recovery values Table 7 and 8 .

Linearity: The method can elicit test result that is directly proportional to analytic concentration within a given range. It is generally reported as the variance of slope or regression line. It is determined by a series of three to six injections of five of more standards. Different levels of solution were prepared and injected to the chromatographic system, and the peak area was measured. Plotted a graph of peak area versus concentration (on $\mathrm{X}$-axis concentration and $\mathrm{Y}$-axis Peak area) and calculate the correlation coefficient. The calibration curve was represented in Fig. 4 and 5, Table 9 and 10.

Limit of Detection: The detection limit of an individual analytical procedure is the lowest amount of analyte in a sample which can be detected but not necessarily quantities as an exact value.

\section{Limit of Detection for the Drugs Ibuprofen \&} Famotidine: The lowest concentration of the sample was prepared concerning the baseline noise and measured the signal to noise ratio. Limit of detection is the lowest concentration of the substance that can be detected, not necessarily quantified by the method. (Regression statistics) The minimum concentration at which the analyte can be detected is determined from the linearity curve by applying the following formula.

$$
\text { Limit of detection }(\mathrm{LOD})=\sigma / \mathrm{S} \times 3.3
$$

Where:

$\mathrm{S}$ - Slope of the calibration curve

$\sigma-$ Residual standard deviation

Limit of Quantification: It is defined as the lowest concentration of an analyte in a sample that can be determined with acceptable precision and accuracy and reliability by a given method under stated experimental conditions. LOQ is expressed as a concentration at a specified signal to noise ratio.

Limit of Quantification for the Drugs Ibuprofen \& Famotidine: The lowest concentration of the sample was prepared concerning the baseline noise and measured the signal to noise ratio. Limit of Quantification is the lowest concentration of the substance that can be estimated quantitatively. It can be determined from the linearity curve by applying the following formula

$$
\text { Limit of Quantification }(\mathrm{LOQ})=\sigma / \mathrm{S} \times 10
$$

Where:

$\mathrm{S}$ - Slope of the calibration curve

$\sigma-$ Residual standard deviation

Robustness: As part of the Robustness, deliberate change in the Flow rate, Mobile Phase composition, Temperature Variation was made to evaluate the impact on the method. The standard and samples of Ibuprofen and Famotidine were injected by changing the conditions of chromatography. There was no significant change in the parameters like resolution, tailing factor, asymmetric factor, and plate count.

The Flow Rate was varied at $1.3 \mathrm{ml} / \mathrm{min}$ to $1.3 \mathrm{ml} / \mathbf{m i n}$ : The Standard solution of Ibuprofen and Famotidine was prepared and analyzed using the varied flow rates along with method developed flow rate. On the evaluation of the above results, it was concluded that the variation in flow rate does not affect the method significantly. Hence, it was indicated that the method was robust even by a change in the flow rate Table $\mathbf{1 1}$ and $\mathbf{1 2}$.

The Organic Composition in the Mobile Phase was Varied from $\mathbf{7 5 \%}$ to $85 \%$ : The Standard solution for the drug Ibuprofen and Famotidine was prepared and analyzed using the varied Mobile phase composition along with the actual mobile 
phase composition. On the evaluation of the above results, it was concluded that the variation in $10 \%$ Organic composition in the mobile phase does not affect the method significantly. Hence it was indicated that the method was robust even by a change in the Mobile phase \pm 10 Table 13 and $\mathbf{1 4}$.

Degradation Studies: ${ }^{20-21}$ The International Conference on Harmonization (ICH) guideline entitled stability testing of new drug substances and products requires that stress testing be carried out to elucidate the inherent stability characteristics of the active substance. Work aimed to perform the stress degradation studies on the Ibuprofen and Famotidine using the proposed method. Drug product and placebo were subjected to forced degradation at various stressed conditions like Hydrolytic degradation under acidic condition, Hydrolytic degradation under alkaline condition, Thermal induced degradation \& Oxidative degradation. All the samples were analyzed for purity peak of Ibuprofen and Famotidine. In all the samples, Peak purity meets the acceptance limits. (Purity angle should be less than purity threshold. Ibuprofen and Famotidine peak should not have any flag in the purity results table (which was analyzed by Waters with Empower-2 software). The results were summarized in Table 1 and 2.

\section{Hydrolytic Degradation Under the Acidic} Condition: $0.49 \mathrm{ml} \& 1.5 \mathrm{ml}$ of Famotidine \& Ibuprofen stock solution was prepared and taken in a clean, dry $10 \mathrm{ml}$ volumetric flask in which $3 \mathrm{ml}$ of $0.1 \mathrm{~N} \mathrm{HCl}$ was added. Then the volumetric flask was kept at the normal condition for $90 \mathrm{~min}$, and further, it was neutralized with $0.1 \mathrm{~N} \mathrm{NaOH}$, and the volume was made up to the mark $[10 \mathrm{ml}]$ with the diluent. The resultant solution was filtered with 0.45 microns syringe filters and placed in the vials.

\section{Hydrolytic Degradation Under the Alkaline} Condition: $0.49 \mathrm{ml} \& 1.5 \mathrm{ml}$ of Famotidine \& Ibuprofen stock solution was prepared and taken in a clean, dry $10 \mathrm{ml}$ volumetric flask in which $3 \mathrm{ml}$ of $0.1 \mathrm{~N} \mathrm{NaOH}$ was added. Then the volumetric flask was kept at the normal condition for $90 \mathrm{~min}$, and further, it was neutralized with $0.1 \mathrm{~N} \mathrm{HCl}$, and the volume was made up to the mark [10ml] with the diluent. The resultant solution was filtered with 0.45 microns syringe filters and placed in the vials.

Thermal-Induced Degradation: $0.49 \mathrm{ml} \& 1.5 \mathrm{ml}$ of Famotidine \& Ibuprofen was prepared and taken in a clean, dry $10 \mathrm{ml}$ volumetric flask in which $3 \mathrm{ml}$ of the diluent was added. Then the volumetric flask was kept at reflux condition for $60 \mathrm{~min}$, and the volume was made up to the mark [10ml] with the same diluent. The resultant solution was filtered with 0.45 microns syringe filters and placed in the vials.

Oxidative Degradation: $0.49 \mathrm{ml} \& 1.5 \mathrm{ml}$ of Famotidine \& Ibuprofen stock solution was prepared and taken in a $10 \mathrm{ml}$ clean, dry volumetric flask in which $1 \mathrm{ml}$ of $3 \% \mathrm{w} / \mathrm{v}$ of hydrogen peroxide solution was added and the volume was made up to the mark with the diluent. Then the volumetric flask was kept at room temperature for $15 \mathrm{~min}$. The resultant solution was filtered with 0.45 microns syringe filters and placed in the vials.

TABLE 1: FORCED DEGRADATION DATA FOR IBUPROFEN

\begin{tabular}{ccccccc}
\hline S. no. & Degradation Studies & Retention Time & Area & Height & Purity Angle & Purity Threshold \\
\hline 1 & Hydrolytic degradation under & 3.624 & 1188296 & 97896 & 0.65 & 1.32 \\
$\quad$ acidic condition & & & & & \\
2 & Hydrolytic degradation under & 3.818 & 1259423 & 103585 & & \\
& alkaline condition & & & & & \\
3 & Thermal induced degradation & 3.861 & 375565 & 33755 & 0.61 & 1.32 \\
4 & Oxidative degradation & 3.860 & 1634693 & 131998 & 0.63 & 1.25 \\
\hline
\end{tabular}

TABLE 2: FORCED DEGRADATION DATA FOR FAMOTIDINE

\begin{tabular}{|c|c|c|c|c|c|c|}
\hline S. no. & Degradation Studies & Retention Time & Area & Height & Purity Angle & Purity Threshold \\
\hline 1 & $\begin{array}{l}\text { Hydrolytic degradation under } \\
\text { acidic condition }\end{array}$ & 1.993 & 113969 & 7169 & 0.80 & 1.51 \\
\hline 2 & $\begin{array}{l}\text { Hydrolytic degradation under } \\
\text { alkaline condition }\end{array}$ & 2.060 & 121060 & 6546 & 0.68 & 1.28 \\
\hline 3 & Thermal induced degradation & 1.973 & 166497 & 13364 & 0.58 & 1.19 \\
\hline 4 & Oxidative degradation & 1.975 & 99046 & 11131 & 0.78 & 1.49 \\
\hline
\end{tabular}


RESULTS \& DISCUSSION: The present work was undertaken to develop and validate a rapid and consistent RP-HPLC method development in which the peaks will appear with a short period as per ICH Guidelines. The proposed method was a simple, fast, accurate, and precise method for the Quantification of the drug in the Pharmaceutical dosage form, bulk drug as well as for routine analysis in Quality control. Overall the proposed method was found to be suitable and accurate for the Quantitative determination of the drug in the tablet dosage form.

The method was simple, precise, accurate and sensitive and applicable for the simultaneous determination of Ibuprofen \& Famotidine in bulk drug and in combined dosage forms. The Highperformance liquid chromatography (RP-HPLC) methods were developed and validated for simultaneous estimation of Ibuprofen \& Famotidine in bulk drug and in combined dosage forms. The RP-HPLC separation was achieved on a Symmetry $\mathrm{C}_{18}(2.1 \times 100 \mathrm{~mm}, 1.7 \mu \mathrm{m}$, Make: $\mathrm{BEH})$ or equivalent in an Isocratic Mode. The mobile phase was composed of Phosphate Buffer (30\%) whose $\mathrm{pH}$ was adjusted to 4.0 by using TEA \& Acetonitrile [HPLC Grade] $(70 \%)$. The flow rate was monitored at $1.2 \mathrm{ml}$ per min. The wavelength was selected for the detection was $236 \mathrm{~nm}$. The run time was $8 \mathrm{~min}$. The retention time found for the drugs Ibuprofen \& Famotidine was 1.887 min. \& 3.615 min. respectively. It was represented in Fig. 3.

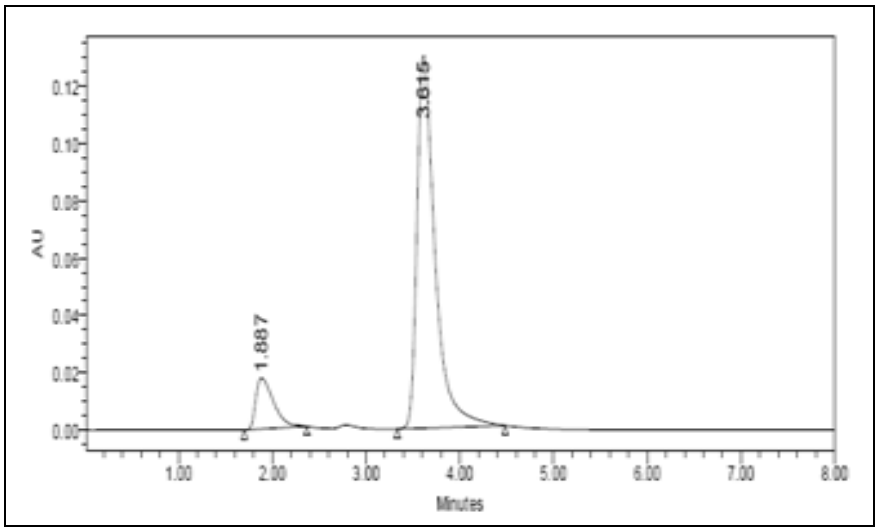

FIG. 3: OPTIMIZATION CHROMATOGRAM FOR IBUPROFEN AND FAMOTIDINE

The Precision data for the drugs Ibuprofen \& Famotidine were represented in Table 1 and 2. The $\%$ RSD for the sample should be NMT 2. The $\%$ RSD for the standard solution was found to be $0.25 \& 1.21$ for the drugs Ibuprofen \& Famotidine respectively, which is within limits; hence the method was precise.

TABLE 3: PRECISION RESULT FOR THE DRUG IBUPROFEN

\begin{tabular}{cc}
\hline Injection & Area \\
\hline Injection-1 & 1591698 \\
Injection-2 & 1599546 \\
Injection-3 & 1596156 \\
Injection-4 & 1594522 \\
Injection-5 & 1589429 \\
Average & 1594270 \\
Standard Deviation & 3921.3 \\
\%RSD & 0.25 \\
\hline
\end{tabular}

TABLE 4: PRECISION RESULT FOR THE DRUG FAMOTIDINE

\begin{tabular}{cc}
\hline Injection & Area \\
\hline Injection-1 & 216449 \\
Injection-2 & 210815 \\
Injection-3 & 210584 \\
Injection-4 & 213409 \\
Injection-5 & 210592 \\
Average & 212370 \\
Standard Deviation & 2573.3 \\
\%RSD & 1.21 \\
\hline
\end{tabular}

TABLE 5: RUGGEDNESS RESULT FOR THE DRUG IBUPROFEN

\begin{tabular}{cc}
\hline Injection & Area \\
\hline Injection-1 & 1679469 \\
Injection-2 & 1681508 \\
Injection-3 & 1643419 \\
Injection-4 & 1624651 \\
Injection-5 & 1649866 \\
Average & 1655783 \\
Standard Deviation & 24391.8 \\
\%RSD & 1.47 \\
\hline
\end{tabular}

TABLE 6: RUGGEDNESS RESULT FOR THE DRUG FAMOTIDINE

\begin{tabular}{cc}
\hline Injection & Area \\
\hline Injection-1 & 220614 \\
Injection-2 & 229991 \\
Injection-3 & 224299 \\
Injection-4 & 225129 \\
Injection-5 & 224163 \\
Average & 224839 \\
Standard Deviation & 3362.5 \\
\%RSD & 1.50 \\
\hline
\end{tabular}

The standard solution with Accuracy $-50 \%$, Accuracy $-100 \%$ and Accuracy $-150 \%$ was injected into the chromatographic system and calculated the amount found and amount added for Ibuprofen and Famotidine and further calculated the individual recovery and mean recovery values Table 5 and $\mathbf{6}$. The \% recovery was found to be $98.4 \%-101.8 \%$ for the drug Ibuprofen. The $\%$ recovery was found to be $98.4 \%$ - $100.5 \%$ for the drug Famotidine. 
TABLE 7: ACCURACY RESULT FOR THE DRUG IBUPROFEN

\begin{tabular}{cccccc}
\hline $\begin{array}{c}\text { \% Concentration } \\
\text { (at specification Level) }\end{array}$ & Area & $\begin{array}{c}\text { Amount Added } \\
(\mathbf{m g})\end{array}$ & $\begin{array}{c}\text { Amount Found } \\
(\mathbf{m g})\end{array}$ & $\begin{array}{c}\text { \% } \\
\text { Recovery }\end{array}$ & $\begin{array}{c}\text { Mean } \\
\text { Recovery }\end{array}$ \\
\hline $50 \%$ & 1695030 & 5.0 & 5.08 & $101.5 \%$ & \\
$100 \%$ & 3284722 & 10.0 & 9.84 & $98.4 \%$ & $100.6 \%$ \\
$150 \%$ & 5100544 & 15.0 & 15.2 & $101.8 \%$ & \\
\hline
\end{tabular}

TABLE 8: ACCURACY RESULT FOR THE DRUG FAMOTIDINE

\begin{tabular}{cccccc}
\hline $\begin{array}{c}\text { \% Concentration } \\
\text { (at specification Level) }\end{array}$ & Area & $\begin{array}{c}\text { Amount Added } \\
(\mathbf{m g})\end{array}$ & $\begin{array}{c}\text { Amount Found } \\
(\mathbf{m g})\end{array}$ & $\begin{array}{c}\text { \% } \\
\text { Recovery }\end{array}$ & $\begin{array}{c}\text { Mean } \\
\text { Recovery }\end{array}$ \\
\hline $50 \%$ & 213703 & 5.0 & 4.9 & $98.4 \%$ & \\
$100 \%$ & 433623 & 10.0 & 9.9 & $99.9 \%$ & $99.6 \%$ \\
$150 \%$ & 654208 & 15.0 & 15.0 & $100.5 \%$ & \\
\hline
\end{tabular}

To test the linearity of the method, five dilutions of the working standard solutions for the drugs Ibuprofen \& Famotidine were prepared. The linearity was established in the range of 100 to 200ppm for the drug Ibuprofen \& 3.32 to6.65ppm for the drug Famotidine. The data were represented in Table 7 and 8.
Each of the dilutions was injected into the column, and the Linearity Curve was represented in Fig. 4 and 5. The Correlation coefficient $\left(\mathrm{R}^{2}\right)$ should not be less than 0.999. The correlation coefficient obtained was 0.999, which was in the acceptance limit.

TABLE 9: LINEARITY RESULT FOR THE DRUG IBUPROFEN

\begin{tabular}{cccc}
\hline S. no. & Linearity Level & Concentration & Area \\
\hline 1 & I & $100 \mathrm{ppm}$ & 1056290 \\
2 & II & $125 \mathrm{ppm}$ & 1320357 \\
3 & III & $150 \mathrm{ppm}$ & 1588900 \\
4 & IV & $175 \mathrm{ppm}$ & 1849003 \\
5 & V & $200 \mathrm{ppm}$ & 2128917 \\
& Correlation Coefficient & & 0.999 \\
\hline
\end{tabular}

TABLE 10: LINEARITY RESULT FOR THE DRUG FAMOTIDINE

\begin{tabular}{cccc}
\hline S. no. & Linearity Level & Concentration & Area \\
\hline 1 & I & $3.32 \mathrm{ppm}$ & 140332 \\
2 & II & $4.15 \mathrm{ppm}$ & 182258 \\
3 & III & $4.98 \mathrm{ppm}$ & 210426 \\
4 & IV & $5.81 \mathrm{ppm}$ & 254916 \\
5 & V & $6.65 \mathrm{ppm}$ & 287232 \\
& Correlation Coefficient & & 0.999 \\
\hline
\end{tabular}

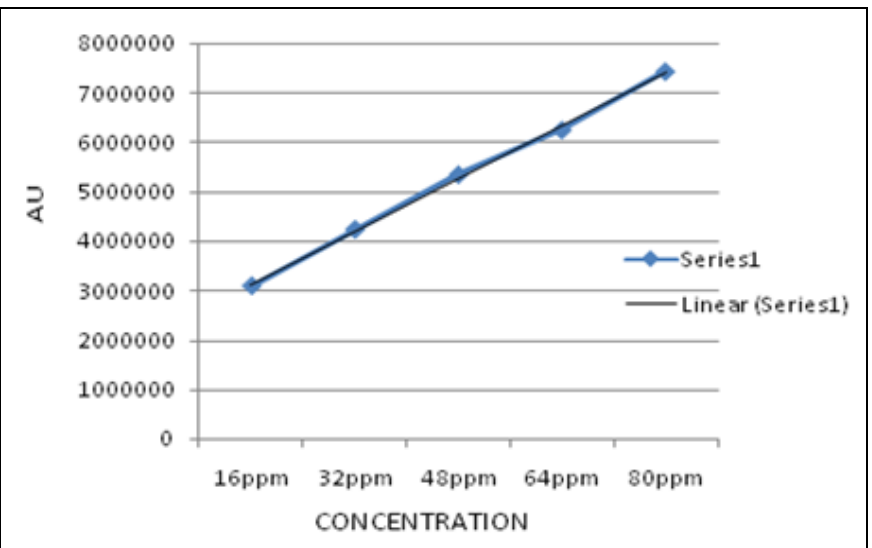

FIG. 4: CALIBRATION CURVE FOR THE DRUG IBUPROFEN

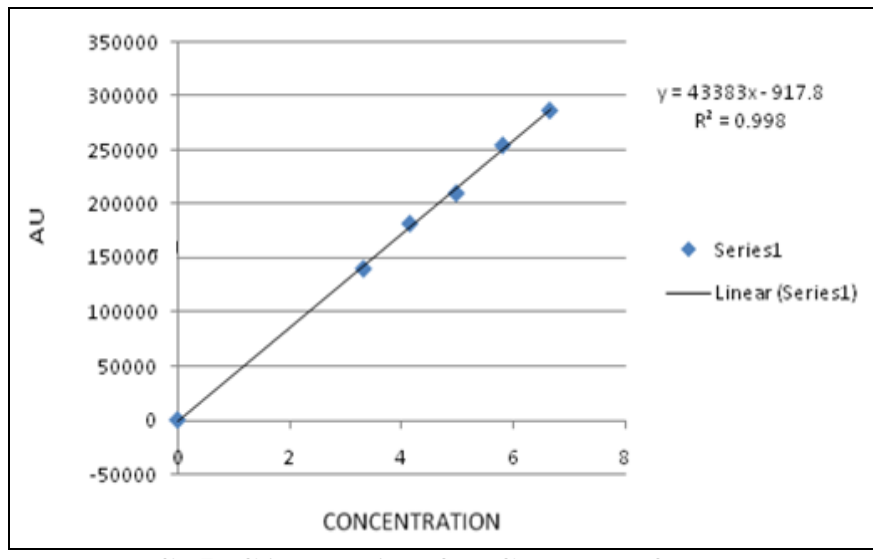

FIG. 5: CALIBRATION CURVE FOR THE DRUG FAMOTIDINE 
The Limit of detection and limit of quantification of the method were calculated basing on a standard deviation of the response and the slope (s) of the calibration curve at approximate levels of the limit of detection and limit of quantification. The LOD for the drugs Ibuprofen \& Famotidine was found to be $0.18 \mu \mathrm{g} / \mathrm{ml}$ and $0.63 \mu \mathrm{g} / \mathrm{ml}$, respectively. The LOQ for the drugs Ibuprofen \& Famotidine was found to be $0.046 \mu \mathrm{g} / \mathrm{ml}$ and $0.15 \mu \mathrm{g} / \mathrm{ml}$, respectively. The Signal to noise ratio should be 3 for LOD. The results obtained were within the limit. The Signal to noise ratio should be 10 for LOQ solution.
The results obtained were within the limit. The Robustness of the method was found out by testing the effect of small, deliberate changes in the chromatographic conditions in the chromatographic conditions and the corresponding peak areas. The factors selected for this purpose were flow rate and percentage composition variation in Phosphate Buffer and Acetonitrile in the mobile phase. The method was found to be robust enough that the peak area was not affected by a small variation in the chromatographic conditions. The system suitability parameters were within limits and shown in Table 9, 10, 11 and 12.

TABLE 11: RESULT FOR EFFECT OF VARIATION IN FLOW RATE FOR THE DRUG IBUPROFEN

\begin{tabular}{cccc}
\hline S. no. & $\begin{array}{c}\text { Flow Rate } \\
(\mathbf{m l} / \text { min })\end{array}$ & USP Plate Count & USP Tailing \\
\cline { 3 - 4 } & 1.1 & 2164 & 1.6 \\
1 & 1.2 & 2189 & 1.5 \\
2 & 1.3 & 2036 & 1.72 \\
\hline
\end{tabular}

TABLE 12: RESULT FOR EFFECT OF VARIATION IN FLOW RATE FOR THE DRUG FAMOTIDINE

\begin{tabular}{cccc}
\hline S. no. & Flow Rate & \multicolumn{2}{c}{ System Suitability Results } \\
\cline { 3 - 4 }$(\mathbf{m l} / \mathbf{m i n})$ & 1.1 & USP Plate Count & USP Tailing \\
\hline 1 & 1.2 & 2068 & 1.7 \\
2 & 1.3 & 2158 & 1.3 \\
3 & 2083 & 1.72 \\
\hline
\end{tabular}

TABLE 13: IT SHOWS THE RESULT FOR EFFECT OF VARIATION IN MOBILE PHASE COMPOSITION FOR THE DRUG IBUPROFEN (ORGANIC PHASE)

\begin{tabular}{cccc}
\hline S. no. & Change in Organic Composition & \multicolumn{2}{c}{ System Suitability Results } \\
\cline { 3 - 4 } in the Mobile Phase & USP Plate Count & USP Tailing \\
\hline 1 & 1.1 & 2087 & 1.9 \\
2 & 1.2 & 2189 & 1.5 \\
3 & 1.3 & 2038 & 1.9 \\
\hline
\end{tabular}

TABLE 14: IT SHOWS THE RESULT FOR EFFECT OF VARIATION IN MOBILE PHASE COMPOSITION FOR THE DRUG FAMOTIDINE (ORGANIC PHASE)

\begin{tabular}{cccc}
\hline S. no. & $\begin{array}{c}\text { Change in Organic Composition } \\
\text { in the Mobile Phase }\end{array}$ & USP Plate Count & USP Tailing \\
\cline { 3 - 4 } & $10 \%$ less & 2078 & 1.9 \\
2 & Actual & 2158 & 1.3 \\
3 & $10 \%$ more & 2096 & 1.8 \\
\hline
\end{tabular}

In order to evaluate the stability of Ibuprofen and Famotidine and ability of the method to separate Ibuprofen and Famotidine from its degradation products, Ibuprofen and Famotidine was subjected to various stress conditions such as Hydrolytic degradation under acidic condition (using $0.1 \mathrm{~N}$ $\mathrm{HCl} \& 0.1 \mathrm{~N} \mathrm{NaOH}$ ), Hydrolytic degradation under alkaline condition (using0.1 N NaOH \& $0.1 \mathrm{~N} \mathrm{HCl),}$ Thermal induced degradation (Reflex condition for $60 \mathrm{~min}$ ), Oxidative degradation (by using $3 \% \mathrm{w} / \mathrm{v}$ of hydrogen peroxide). (Purity angle should be less than purity threshold. Ibuprofen and Famotidine peak should not have any flag in the purity results table (For Waters Empower-2 software). The results were summarized in Table 1 and 2. The following chromatograph represents the degradation studies for the drug [Ibuprofen and Famotidine] which were represented in Fig 6, 7, 8 and 9. 


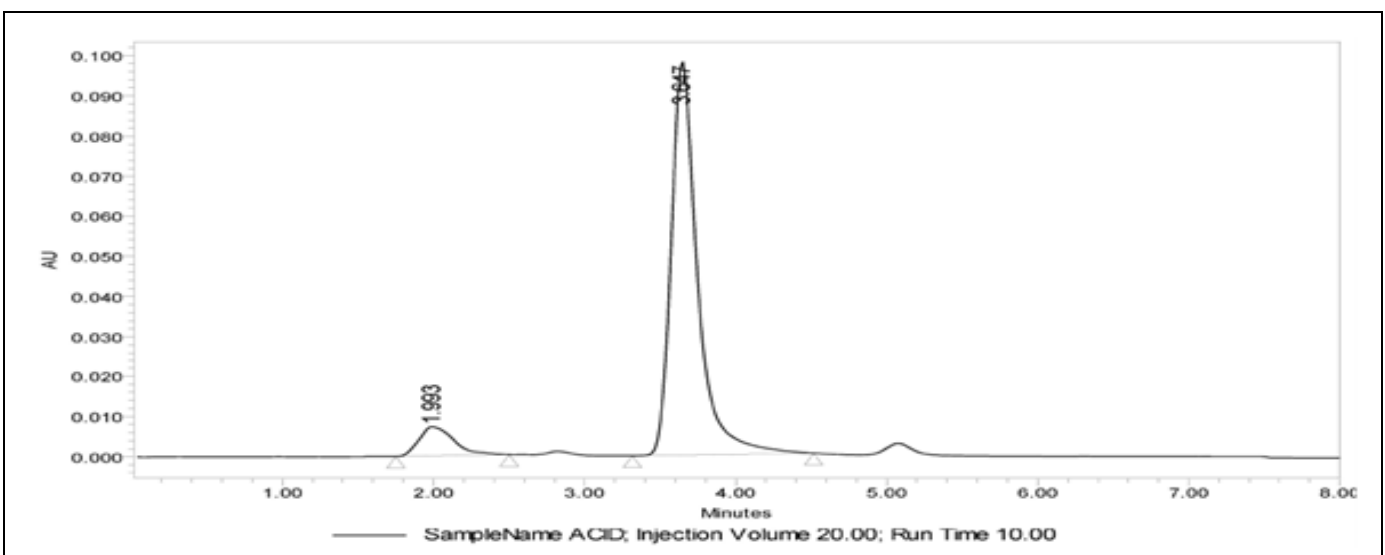

FIG. 6: THE CHROMATOGRAPH REPRESENTS THE HYDROLYTIC DEGRADATION UNDER ACIDIC CONDITION

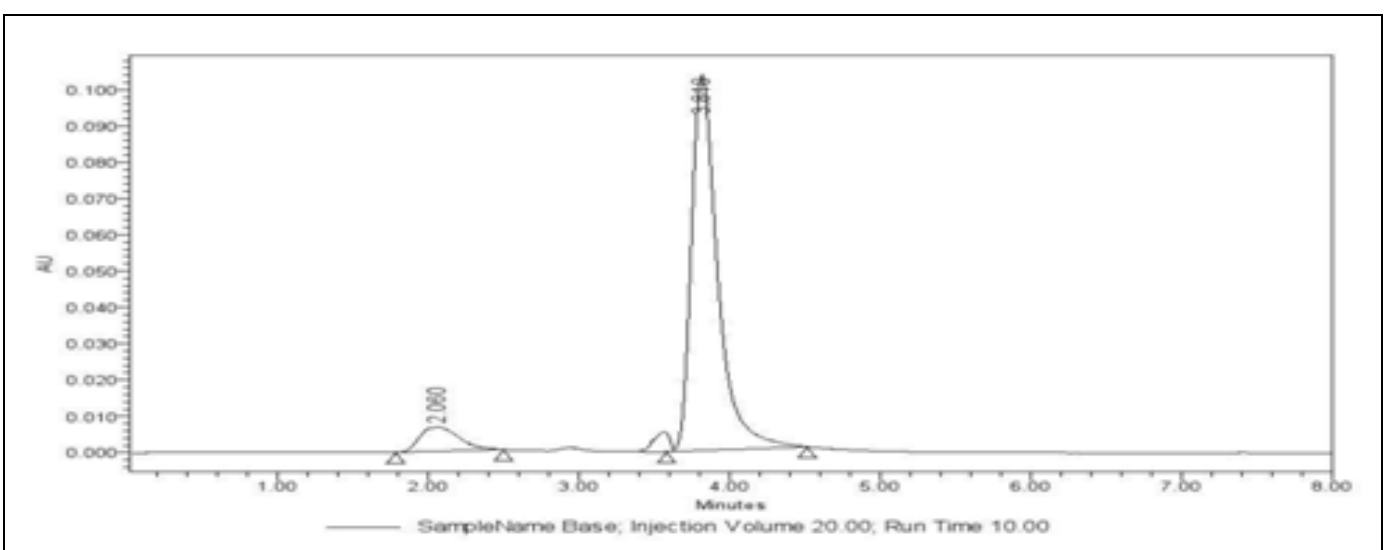

FIG. 7: THE CHROMATOGRAPH REPRESENTS THE HYDROLYTIC DEGRADATION UNDER ALKALINE CONDITION

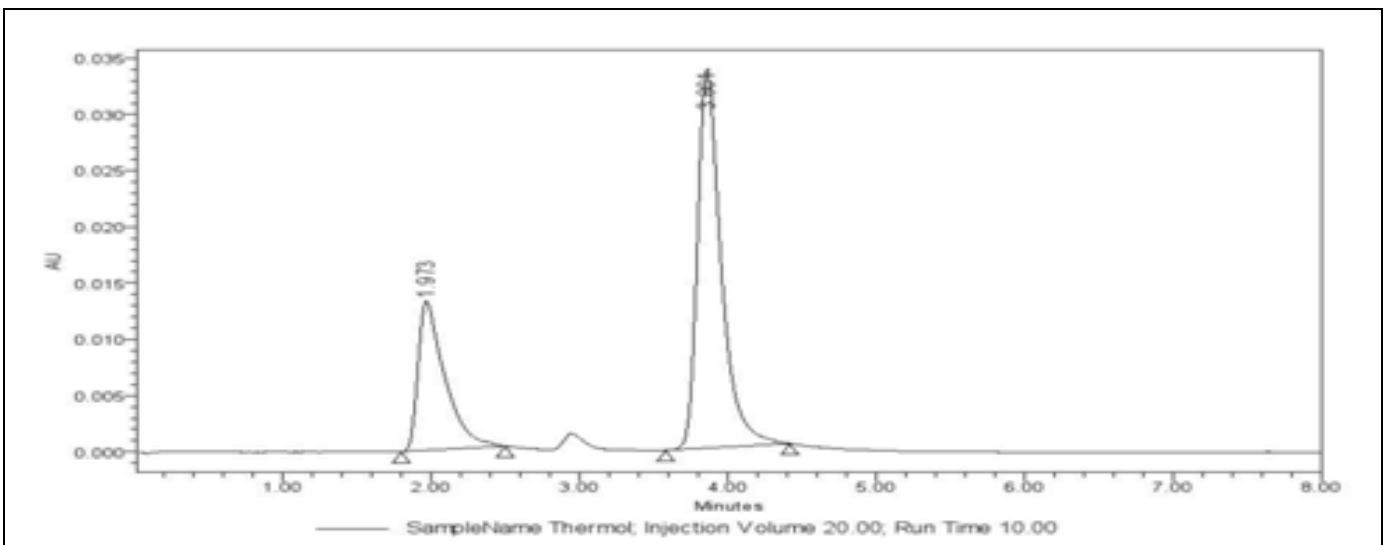

FIG. 8: THE CHROMATOGRAPH REPRESENTS THE THERMAL INDUCED DEGRADATION

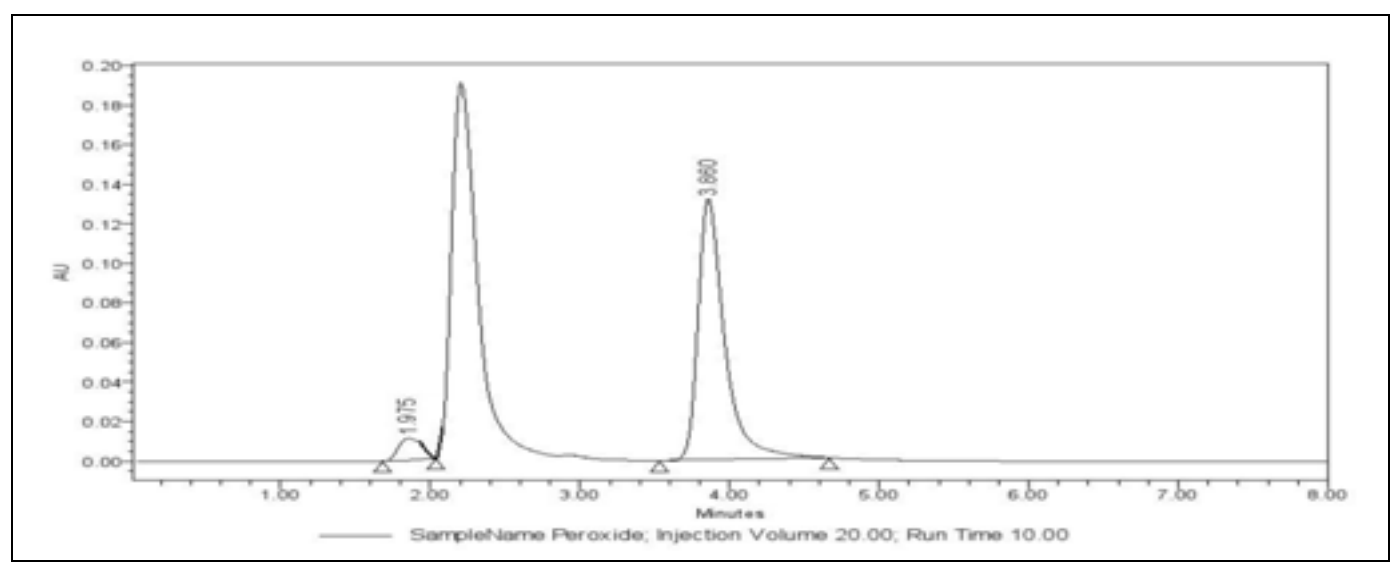

FIG. 9: THE CHROMATOGRAPH REPRESENTS THE OXIDATIVE DEGRADATION 
CONCLUSION: Development of new analytical methods for the determination of drugs in pharmaceutical dosage is important in pharmacokinetic, toxicological biological studies. Pharmaceutical analysis occupies a pivotal role in statuary certification of drugs and their formulations either by the industry or by the regulatory authorities. In industry, the quality assurance and quality control departments play a major role in bringing out a safe and effective drug or dosage form.

The current good manufacturing practices (CGMP) and the Food Drug Administration (FDA) guidelines insist for the adoption of sound methods of analysis with greater sensitivity and reproducibility. Therefore, the complexity of problems encountered in pharmaceutical analysis with the importance of achieving the selectivity, speed, low cost, simplicity, sensitivity, specificity, precision, and accuracy in the estimation of drugs. It was concluded that the proposed new UPLC method developed for the quantitative determination of Ibuprofen \& Famotidine in bulk as well as in its formulations was simple, selective, sensitive, accurate, precise, and rapid.

The method was proved to be superior to most of the reported methods. The mobile phases were simple to prepare and economical. The sample recoveries in the formulation were in good agreement with their respective label claims. Application of this method for estimation of Ibuprofen \& Famotidine from the tablet dosage form and stressed samples showed that neither the degradation products nor the excipients interfered in the estimation of the drug. Hence, this method was specific, stability-indicating, and can be successfully used for the estimation of the drug in bulk and pharmaceutical dosage forms.

Hence, the method can be easily adopted as an alternative method to report routine determination of Ibuprofen \& Famotidine depending upon the availability of chemicals and nature of other ingredients present in the sample. The method also finds use in clinical, biological, and pharmacokinetic studies for the drug Ibuprofen \& Famotidine. The method was validated as per ICH guidelines, and validation acceptance criteria were met in all cases.
FUTURE ASPECT: The proposed method can be used in the future for the clinical, biological, and pharmacokinetic studies of Ibuprofen \& Famotidine.

\section{ACKNOWLEDGEMENT: Nil}

\section{CONFLICT OF INTEREST: Nil}

\section{REFERENCES:}

1. http://www.rxlist.com/ibuprofen-drug.htm.

2. http://www.rxlist.com/pepcid-drug.htm.

3. Rang HP and Dale MM: Pharmacology, $3^{\text {rd }}$ edition, 2003.

4. The Indian Pharmacopoeia commission, Indian Pharmacopoeia Vol II, The Indian Pharmacopoeia commission, Ghaziabad, India, 2007.

5. The Stationery office, British Pharmacopoeia Vol. III, The Stationery office, London, UK, 2009.

6. United States Pharmacopoeial Convention. Committee of Revision, United States Pharmacopoeia and National Formulary, United States Pharmacopoeial Convention, Rockville, Md, USA, $27^{\text {th }}$ edition, 2004.

7. Reddy PB and Reddy MS: RP-HPLC method for simultaneous estimation of paracetamol and ibuprofen in tablets. Asian Jour of Res in Chem 2009; 2(1): 70-72.

8. Chitlange S, Sakarkar D, Wankhede S and Wadodkar S: High-performance thin layer chromatographic method for simultaneous estimation of ibuprofen and pseudoephedrine hydrochloride. Indian Journal of Pharmaceutical Sciences 2008; 70(3): 398-00.

9. Solomon WDS, Kumar RA, Anand PRV, Sivakumar R, and Venkatnarayanan R: Derivatized HPTLC method for simultaneous estimation of glucosamine and ibuprofen in tablets. Journal of Pharmaceutical Research and Health Care 2010; 2(2): 156-62.

10. Rele RV and Sawant SA: Determination of paracetamol and ibuprofen from combined dosage formulation by HPTLC method. Analytical Chemistry 2010; 9(1): 302-05.

11. Bari VR, Dhorda UJ and Sundaresan M: A simultaneous packed column supercritical fluid chromatographic method for ibuprofen, Chlorzoxazone and acetaminophen in bulk and dosage forms. Talanta 1997; 45(2): 297-02.

12. Gondalia R, Mashru R and Savaliya P: Development and validation of Spectrophotometric methods for simultaneous estimation of ibuprofen and paracetamol in soft gelatin capsule by simultaneous equation method. Int Jou of Chem Tech Research 2010; 2(4): 1881-85.

13. Najma S, Mahwish A, Shamim GS and Somia: Determination of moxifloxacin and famotidine in pharmaceutical dosage formulations by RP HPLC: application to in-vitro drug interactions. Química Nova 2011; 34(4): 683-88.

14. Novaković J: High-performance thin-layer chromatography for the determination of ranitidine hydrochloride and famotidine in pharmaceuticals," Journal of Chromatography A 1999; 846(1-2): 193-98.

15. Kanakapura B, Okram ZD and Pavagada J: Simple and sensitive UV Spectrophotometric methods for determination of famotidine in table formulations," Farmacia 2011; 59: 647-56.

16. Gracy S, Kumar SA, Debnath M, Rao JVLNS, Sankar DG, Mounika TA: RP-HPLC analytical method development and validation for simultaneous estimation of ibuprofen and famotidine in bulk as well in pharmaceutical dosages 
form by using PDA detector. Int Res J Pharm 2014; 5(4): 3000-05. http://dx.doi.org/10.7897/2230-8407.050464.

17. Geneva: IFPMA; International Conference on Harmonization. Text on Validation of Analytical Procedures: Term and definition Q2A, International Conference on Harmonization 1996.

18. Geneva: IFPMA; 1997. International Conference on Harmonization. Validation of Analytical Procedures: Methodology Q2B, International Conference on Harmonization 1197.
19. Geneva: IFPMA; International Conference on Harmonization. Photostability testing of new drug substance and products Q1B, International Conference on Harmonization 1996.

20. ICH harmonized tripartite guideline. Impurities in New Drug products Q3B (R2) current step 4 versions dated 2 June 2006

21. ICH, Q1A (R2), Stability Testing of New Drug Substances and Products, Geneva, Feb. 2003.

\section{How to cite this article:}

Kumar SA, Debnath M, Rao JVLNS and Sankar DG: A new RP-HPLC stability indicating method development and validation for simultaneous estimation of ibuprofen \& famotidine in bulk as well in pharmaceutical dosages form by using PDA detector. Int J Pharm Sci \& Res 2014; 5(9): 3829-39. doi: 10.13040/IJPSR.0975-8232.5(9).3829-39.

All @ 2013 are reserved by International Journal of Pharmaceutical Sciences and Research. This Journal licensed under a Creative Commons Attribution-NonCommercial-ShareAlike 3.0 Unported License.

This article can be downloaded to ANDROID OS based mobile. Scan QR Code using Code/Bar Scanner from your mobile. (Scanners are available on Google Playstore) 